\title{
Effects of spermidine supplementation on cognition and biomarkers in older adults with subjective cognitive decline (SmartAge)—study protocol for a randomized controlled trial
}

Miranka Wirth 1,2,3,4+ (D), Claudia Schwarz ${ }^{1,2+}$, Gloria Benson ${ }^{1,2+}$, Nora Horn ${ }^{1,2}$, Ralph Buchert ${ }^{5,6}$, Catharina Lange ${ }^{5}$, Theresa Köbe ${ }^{1,2,7,8}$, Stefan Hetzer ${ }^{9,10}$, Marta Maglione ${ }^{2,11}$, Eva Michael ${ }^{2,11}$, Stefanie Märschenz ${ }^{2}, K_{\text {nnut Mai }}{ }^{12,13}$, Ute Kopp ${ }^{1}$, Dietmar Schmitz ${ }^{2,14}$, Ulrike Grittner ${ }^{15,16}$, Stephan J. Sigrist ${ }^{2,11,14}$, Slaven Stekovic ${ }^{17}$, Frank Madeo ${ }^{17,18^{*}}$ and Agnes Flöel ${ }^{19,20^{*}}$

\begin{abstract}
Background: Given the global increase in the aging population and age-related diseases, the promotion of healthy aging is one of the most crucial public health issues. This trial aims to contribute to the establishment of effective approaches to promote cognitive and brain health in older individuals with subjective cognitive decline (SCD). Presence of SCD is known to increase the risk of objective cognitive decline and progression to dementia due to Alzheimer's disease. Therefore, it is our primary goal to determine whether spermidine supplementation has a positive impact on memory performance in this at-risk group, as compared with placebo. The secondary goal is to examine the effects of spermidine intake on other neuropsychological, behavioral, and physiological parameters.

Methods: The SmartAge trial is a monocentric, randomized, double-blind, placebo-controlled phase IIb trial. The study will investigate 12 months of intervention with spermidine-based nutritional supplementation (target intervention) compared with 12 months of placebo intake (control intervention). We plan to recruit 100 cognitively normal older individuals with SCD from memory clinics, neurologists and general practitioners in private practice, and the general population. Participants will be allocated to one of the two study arms using blockwise randomization stratified by age and sex with a 1:1 allocation ratio. The primary outcome is the change in memory performance between baseline and post-intervention visits (12 months after baseline). Secondary outcomes include the change in memory performance from baseline to follow-up assessment (18 months after baseline), as well as changes in neurocognitive, behavioral, and physiological parameters (including blood and neuroimaging biomarkers), assessed at baseline and post-intervention.

(Continued on next page)
\end{abstract}

\footnotetext{
*Correspondence: frank.madeo@uni-graz.at; agnes.floeel@uni-greifswald.de

${ }^{+}$Miranka Wirth, Claudia Schwarz, and Gloria Benson contributed equally to

this work.

${ }^{17}$ Institute of Molecular Biosciences, University of Graz, NAWI Graz, Graz,

Austria

${ }^{19}$ Department of Neurology, University Medicine Greifswald, Greifswald,

Germany

Full list of author information is available at the end of the article
}

(c) The Author(s). 2019, corrected publication 2022. Open Access This article is distributed under the terms of the Creative Commons Attribution 4.0 International License (http://creativecommons.org/licenses/by/4.0/), which permits unrestricted use, distribution, and reproduction in any medium, provided you give appropriate credit to the original author(s) and the source, provide a link to the Creative Commons license, and indicate if changes were made. The Creative Commons Public Domain Dedication waiver (http://creativecommons.org/publicdomain/zero/1.0/) applies to the data made available in this article, unless otherwise stated. 


\begin{abstract}
(Continued from previous page)
Discussion: The SmartAge trial aims to provide evidence of the impact of spermidine supplementation on memory performance in older individuals with SCD. In addition, we will identify possible neurophysiological mechanisms of action underlying the anticipated cognitive benefits. Overall, this trial will contribute to the establishment of nutrition intervention in the prevention of Alzheimer's disease.

Trial registration: ClinicalTrials.gov, NCT03094546. Registered 29 March 2017-retrospectively registered.

Protocol version: Based on EA1/250/16 version 1.5
\end{abstract}

Keywords: Dietary supplementation, Polyamines, Aging, Memory, Health, Autophagy, Nutrition

\section{Background}

Longer life expectancy has led to a growth of the older population, with individuals aged 60 and older expected to reach about $20 \%$ of the population in high-income countries [1]. This demographic change is associated with increased rates of age-related diseases, such as dementia due to Alzheimer's disease (AD). The most prevalent form of late-onset dementia is expected to triple by the year 2050 [2], which will pose a high social and economic impact on patients, caregivers, and society in general. Importantly, around one third of these cases worldwide are attributed to potentially modifiable risk factors [3]. The development of effective strategies that help to prevent age- and disease-related worsening of brain structure and function may thus provide significant benefits for society and health-care systems.

\section{Subjective cognitive decline: a target group for early intervention}

Subtle neuropathological alterations related to $\mathrm{AD}$ are suggested to start decades before the onset of clinical symptoms $[4,5]$. One early sign of pathological brain aging is the manifestation of subjective cognitive decline (SCD). In cognitively unimpaired older individuals, the presence of SCD is associated with a higher risk for objective cognitive decline and clinical progression to symptomatic disease stages [6-9]. Moreover, individuals with SCD harbor increased $\beta$-amyloid $(\mathrm{A} \beta$ ) deposition [10], gray matter volume reduction [11-13], and neural dysfunction [14] in brain regions typically affected in AD. Thus, SCD has been conceptualized to occur at a late preclinical stage of $\mathrm{AD}$ [15], where aberrant brain changes are present [16] in the absence of objective cognitive impairment. This at-risk group is recognized as an eligible target population for early intervention strategies $[15,17]$, aiming to protect against neuropathological alterations, to restore functional and structural brain health, and to maintain cognitive abilities as long as possible.

\section{Spermidine and its implication in healthy aging}

Healthy lifestyle behaviors, including physical activity, cognitive attainment, and a healthy diet, are proposed to protect against age- and disease-related brain changes and, thereby, preserve cognitive functioning [18-22]. Caloric restriction, among others, appears to be effective to improve memory performance in the elderly [23] and induce favorable neural changes in the hippocampal network [24]. Novel candidate substances proposed to mimic such beneficial effects in aging organisms are natural polyamines, in particular, spermidine and spermine $[25,26]$. Organic compounds play an important role in the maintenance of basic cellular functions like cell growth, survival, and proliferation [27]. Beyond these "microscopic" actions, there is an indication that polyamines influence "macroscopic" systems underlying learning and memory as well as age-related changes of this cognitive function. In rodent models, polyamine levels in the hippocampus are shown to be associated with memory retrieval and formation [28] and change with age in certain brain areas, including medial-temporal memory structures [29]. Lastly, the reduction of spermidine in the brain of aged flies is paralleled by memory decline [30].

Given these observational findings, it has been hypothesized that external supply of polyamines may protect against age-related memory loss. Indeed, a first study in aging fruit flies showed that spermidine-rich diet restored endogenous spermidine levels and thereby rescued memory performance [30]. This beneficial effect of spermidine intake appears to be mediated by several protective pathways [31]. For example, spermidine may act through autophagy to regulate synaptic transmission/plasticity [32] and clear cellular "waste" including pathogenic protein aggregates [30]. Nutritional spermidine is also associated with a number of cardio-protective [33] and anti-inflammatory [34] actions, which may help to preserve higher-order brain functions. Overall, these findings in aging model organisms have suggested a promising role of spermidine in the promotion of brain and cognitive health.

\section{Spermidine supplementation in older adults with SCD: initial evidence}

Spermidine supplementation is thus proposed to open a new avenue in the protection and restoration of memory 
abilities in higher age. This expected benefit is of particular need in older individuals at risk for the development of dementia. It is, however, unknown whether the memory-promoting effect of spermidine is detectable in humans and to what extent this effect may be attributed to the influence of spermidine on biomarkers of healthy aging. An initial study showed that polyamine-enriched diet over 2 months increased blood spermidine levels in healthy middle-aged men [35]. Our group has conducted a first 3-month phase IIa trial with nutritional spermidine in 30 older adults with SCD (ClinicalTrials.gov identifier NCT02755246). Trial outcomes demonstrated high compliance, tolerance, and safety profiles as well as preliminary efficacy of the administered spermidine-rich plant extract [36, 37]. Specifically, we found a moderate enhancement of memory performance, measured using the mnemonic similarity task (MST) [38], in the spermidine-treated group compared with placebo intervention. This computer-based task is a sensitive measure of subtle cognitive changes induced by targeted interventions in the memory system [39]. In the pilot trial, we did not detect intervention effects on standard neuropsychological tests of memory or executive functions [37]. At this point, longer-term intervention studies with sufficient sample size are required to validate the therapeutic potential of nutritional spermidine against memory loss in older individuals and delineate possible neurophysiological mechanisms of action.

\section{Choice of comparator}

A placebo comparator will be implemented in this study, in correspondence with our previous trial [36]. The present trial will use microcrystalline cellulose as a comparator condition. Beside randomization and double blinding, placebo-controlled trials allow to minimize the risk of bias and to maximize the verification of the effect of the verum intervention [40]. Our placebo capsules will be identical to the verum intervention in shape, color, taste, and smell, but contain no active ingredients. The World Health Organization (WHO) and the US Food and Drug Administration (FDA) recognize that the use of cellulose as a food additive is safe and well tolerated in animal models and humans.

\section{Objective and purpose of the SmartAge trial}

We will conduct a randomized controlled trial with a 12-month spermidine supplementation in cognitively unimpaired older individuals with $\operatorname{SCD}(n=100)$. The primary objective of the SmartAge trial is to provide evidence of a beneficial impact of nutritional spermidine on memory performance (primary outcome) at the end of the intervention, as compared with placebo. Second, we aim to examine whether spermidine intake has positive effects on memory performance after an additional 6-month follow-up period without further supplementation as well as on other age-relevant cognitive domains, lifestyle behaviors, psycho-affective characteristics, and perceived quality of life. This data will help to estimate potential benefits of nutrition intervention on well-being and everyday life. Third, this trial will identify possible mechanisms of action underlying the proposed spermidine-associated benefits on cognition using indicators of autophagy, blood-based biomarkers, and neuroimaging parameters of brain structure and function. Finally, the study will assess potential moderators of the intervention effect, such as age-related neuropathologies as well as genetic polymorphisms. Overall, the SmartAge trial aims to establish a significant milestone in the implementation of early intervention strategies in older individuals at risk of dementia due to $\mathrm{AD}$.

\section{Methods: participants, intervention, and outcomes}

Trial design and setting

This is a monocentric, randomized, double-blind, placebo-controlled phase IIb trial, carried out at the NeuroCure Clinical Research Center, Charité - Universitätsmedizin Berlin.

The trial includes 12 months of intervention with spermidine supplementation (target intervention) compared with 12 months of placebo intake (control intervention). The trial will compare outcomes of the two intervention groups, with participants randomized to one of the two study arms. Randomization is performed blockwise with a 1:1 allocation ratio. The SmartAge trial has been approved by the responsible Institutional Review Board and will be carried out in compliance with institutional ethical standards and the Declaration of Helsinki.

\section{Eligibility criteria}

The main inclusion criteria for potential participants in the SmartAge study are:

1. Age, $60-90$ years

2. Presence of SCD in accordance with research criteria, recommended by the international SCD-I working group for studies on SCD [15]: the expression of subjective cognitive complaints for at least 6 months and associated concerns (worries), affirmation to consult and/or previous consultation of a doctor due to these symptoms, normal cognitive performance, and no restrictions on activities of daily living

3. Ability to provide written informed consent

4. Health insurance coverage to clarify possible incidental findings 
We will exclude potential participants in case one or more of the following criteria are present:

1. Dementia, according to the Diagnostic and Statistical Manual of Mental Disorders, 4th Edition (DSM-IV) [41]

2. Mild cognitive impairment (MCI), according to clinical diagnostic criteria [42]

3. Severe or untreated medical disorders (advanced cardiac or respiratory disease, severe liver, kidney or metabolic diseases, untreated thyroid dysfunctions or untreated diabetes mellitus), psychiatric disorders (untreated depression, psychosis) or neurological disorders (epilepsy, clinically manifest stroke)

4. Malignancies currently or as indicated by medical history (exception: basalioma)

5. Drug abuse or alcohol dependency

6. Current polyamine substitution and/or participation in respective intervention studies

7. Known intolerance or allergies to wheat germs, gluten or histamine

8. Contraindications to imaging techniques: claustrophobia, metallic implants (e.g., intracranial metal clips), electronic devices (e.g., cardiac pacemakers), or permanent tattoos

9. With regard to positron emission tomography (PET) assessments (optional consent): participation in another study with the use of ionizing radiation within the last 3 months

10. With regard to muscle biopsy assessments (optional consent): allergy or intolerance to the local anesthetic (lidocaine), coagulation disorders, current therapy with antiplatelet or anticoagulation drugs (e.g., clopidogrel, aspirin, vitamin $\mathrm{K}$ antagonist, new oral anticoagulant drugs) or steroids, current thrombosis, or other severe diseases of the lower extremities that precludes muscle biopsy

In case written informed consent is provided and all eligibility criteria are met, participants will be included in the study.

\section{Intervention}

Participants will receive nutrition intervention over 12 months with either spermidine or placebo supplementation. The dietary supplement used in the target intervention is a polyamine-rich plant extract [36], produced using an extraction method developed and optimized by TLL The Longevity Labs (Graz, Austria). The extraction method will obtain polyamines from wheat germs without the application of acids, organic solvents, and/or potentially harmful chemicals. Wheat germs serve as raw material for the extraction process, because they contain a high concentration of polyamines, in particular, spermidine [43].

The plant extract to be administered is mainly enriched by spermidine and spermine (with $1.2 \mathrm{mg}$ spermidine and $0.6 \mathrm{mg}$ spermine per $1 \mathrm{~g}$ extract). Furthermore, $1 \mathrm{~g}$ of extract contains $0.2 \mathrm{mg}$ putrescine, < $0.005 \mathrm{mg}$ cadaverine, and $0.166 \mathrm{mg} \mathrm{L}$-ornithine. In combination with a normal diet, the intake of the planned daily dose of $750 \mathrm{mg}$ extract (even in the case of multiple overdoses) is below the calculated no observed adverse effects level (NOAEL) for humans of $29 \mathrm{mg} / \mathrm{kg}$ body weight (bw)/day for cadaverine and putrescine [44]. This is also the case for spermidine and spermine, where the NOAEL is $13.5 \mathrm{mg} / \mathrm{kg}$ bw/day or $3.1 \mathrm{mg} / \mathrm{kg}$ bw/day [44]. The NOAEL for L-ornithine in humans is above $500 \mathrm{mg} /$ $\mathrm{kg}$ bw/day [45], and thus remains unattainable in the planned extract administration. The safety of the spermidine-rich extract for the use in humans was evaluated prior to the SmartAge trial by a chemical analysis (unpublished data) and a translational study on safety and tolerability [36].

In the intervention group, the spermidine supplement will be administered daily in the form of six capsules, each containing $125 \mathrm{mg}$ extract, resulting in a daily dose of $750 \mathrm{mg}$ extract or $0.9 \mathrm{mg}$ spermidine, $0.5 \mathrm{mg}$ spermine, $0.2 \mathrm{mg}$ putrescine, $<0.004 \mathrm{mg}$ of cadaverine, and $0.12 \mathrm{mg}$ of L-ornithine. This amount of daily polyamine intake accounts for an increase of approximately 10 $20 \%$ of the average spermidine intake in industrial countries [46]. The dosage is within the amount of polyamines administered in an earlier intervention study [35], using approximately $10 \mathrm{mg} /$ day of dietary spermidine in humans. The amount would also be obtainable by well-targeted diets (e.g., $200 \mathrm{~g}$ of cooked soybeans [47]). The control group will receive placebo capsules, six per day, filled with $750 \mathrm{mg}$ cellulose in sum.

Participants of both groups (spermidine and placebo) are instructed to follow a regular capsule intake per day, two capsules with each main meal (breakfast, lunch, dinner), and to maintain their dietary habits during the time of intervention. Participants will be supplied with capsules throughout the intervention period. To ensure trial compliance, we closely monitor capsule intake throughout the trial (see the "Intervention period" section).

\section{Assessment of study measures Measures assessed at baseline}

Assessments of following participant's characteristics will be conducted at baseline, summarized in Table 1: (a) demographic information including age, civil status, and education; (b) information on family history focused on $\mathrm{AD}$, other non-specified subtypes of dementia, idiopathic Parkinson's disease, and stroke; and (c) behavioral measures of subjective cognition function, lifelong 
Table 1 SmartAge study outcome assessment

\begin{tabular}{|c|c|c|c|c|c|c|}
\hline Time point & Measurement & Mode & V0 & $\mathrm{V} 1$ & $\mathrm{~V} 2$ & V3 \\
\hline \multicolumn{7}{|l|}{ Enrollment } \\
\hline Eligibility screening & & Telephone & $x$ & & & \\
\hline \multirow[t]{5}{*}{ Screening assessment } & MMSE [85] & $\begin{array}{l}\text { On-site } \\
\text { paper }\end{array}$ & $x$ & & $x$ & $x$ \\
\hline & Logical Memory [53] & $\begin{array}{l}\text { On-site } \\
\text { paper }\end{array}$ & $x$ & & $x$ & $x$ \\
\hline & TMT A [54] & $\begin{array}{l}\text { On-site } \\
\text { paper }\end{array}$ & $x$ & & $x$ & $x$ \\
\hline & GDS $[56,86]$ & $\begin{array}{l}\text { On-site } \\
\text { paper }\end{array}$ & $x$ & & $x$ & $x$ \\
\hline & IADL [55] & $\begin{array}{l}\text { On-site } \\
\text { paper }\end{array}$ & $x$ & & $x$ & $x$ \\
\hline Signed informed consent & & On-site & $x$ & & & \\
\hline Allocation/randomization & & & & $x$ & & \\
\hline \multicolumn{7}{|l|}{ Intervention } \\
\hline \multicolumn{7}{|l|}{ Assessments } \\
\hline \multicolumn{7}{|l|}{ Baseline variables } \\
\hline Demographic information & Age, civil status, education & $\begin{array}{l}\text { On-site } \\
\text { paper }\end{array}$ & & $x$ & & \\
\hline Family history & Dementia, Parkinson disease, and stroke & $\begin{array}{l}\text { On-site } \\
\text { paper }\end{array}$ & & $x$ & & \\
\hline Subjective cognitive function & ECog-39 [87] & $\begin{array}{l}\text { On-site } \\
\text { paper }\end{array}$ & & $x$ & & \\
\hline \multirow[t]{2}{*}{ Lifestyle (lifelong) } & LEQ [88] & $\begin{array}{l}\text { At-home } \\
\text { paper }\end{array}$ & & $x$ & & \\
\hline & CAI [89] & $\begin{array}{l}\text { On-site } \\
\text { interview }\end{array}$ & & $x$ & & \\
\hline \multirow[t]{2}{*}{ Personality } & BFI-10 [90] & $\begin{array}{l}\text { On-site } \\
\text { paper }\end{array}$ & & $x$ & & \\
\hline & SVF-78 [91] & $\begin{array}{l}\text { On-site } \\
\text { paper }\end{array}$ & & $x$ & & \\
\hline Hand preference & Oldfield Hand Preference [92] & $\begin{array}{l}\text { On-site } \\
\text { paper }\end{array}$ & & $x$ & & \\
\hline Premorbid IQ & MWT [93] & $\begin{array}{l}\text { On-site } \\
\text { paper }\end{array}$ & & $x$ & & \\
\hline Genetic markers & APOE $\varepsilon 4$ status & On-site & & $x$ & & \\
\hline Cerebral PET (optional consent) & $A \beta$ status & On-site & & $x$ & & \\
\hline \multicolumn{7}{|l|}{ Primary outcome } \\
\hline Memory & MST [38] & $\begin{array}{l}\text { On-site } \\
\text { Computer }\end{array}$ & & $x$ & $x$ & $x$ \\
\hline \multicolumn{7}{|l|}{ Secondary outcomes } \\
\hline \multirow[t]{2}{*}{ Memory } & VLMT [94] & $\begin{array}{l}\text { On-site } \\
\text { paper }\end{array}$ & & $x$ & $x$ & $x$ \\
\hline & Doors and People [95] & $\begin{array}{l}\text { On-site } \\
\text { paper }\end{array}$ & & $x$ & $x$ & $x$ \\
\hline \multirow[t]{3}{*}{ Executive function } & Digit Symbol [96] & $\begin{array}{l}\text { On-site } \\
\text { paper }\end{array}$ & & $x$ & $x$ & $x$ \\
\hline & TMT B [54] & $\begin{array}{l}\text { On-site } \\
\text { paper }\end{array}$ & & $x$ & $x$ & $x$ \\
\hline & Block Tapping [97] & $\begin{array}{l}\text { On-site } \\
\text { paper }\end{array}$ & & $x$ & $x$ & $x$ \\
\hline
\end{tabular}


Table 1 SmartAge study outcome assessment (Continued)

\begin{tabular}{|c|c|c|c|c|c|c|}
\hline Time point & Measurement & Mode & V0 & $\mathrm{V} 1$ & V2 & V3 \\
\hline & Stroop [98] & $\begin{array}{l}\text { On-site } \\
\text { paper }\end{array}$ & & $x$ & $x$ & $x$ \\
\hline \multirow[t]{2}{*}{ Attention } & Digit Span [96] & $\begin{array}{l}\text { On-site } \\
\text { paper }\end{array}$ & & $x$ & $x$ & $x$ \\
\hline & TAP [99] subtests: alertness and divided attention & $\begin{array}{l}\text { On-site } \\
\text { Computer }\end{array}$ & & $x$ & $x$ & \\
\hline \multirow[t]{2}{*}{ Language } & Semantic/Phonemic Fluency [100] & On-site & & $x$ & $x$ & $x$ \\
\hline & Boston Naming Test [100] & $\begin{array}{l}\text { On-site } \\
\text { paper }\end{array}$ & & $x$ & $x$ & $x$ \\
\hline \multicolumn{7}{|l|}{ Lifestyle (current) } \\
\hline Physical activity & FKA [101] & $\begin{array}{l}\text { At-home } \\
\text { paper }\end{array}$ & & $x$ & $x$ & $x$ \\
\hline Cognitive activity & CAl Present [89] & $\begin{array}{l}\text { On-site } \\
\text { interview }\end{array}$ & & $x$ & $x$ & $x$ \\
\hline Sleep quality & PSQI [102] & $\begin{array}{l}\text { At-home } \\
\text { paper }\end{array}$ & & $x$ & $x$ & $x$ \\
\hline \multirow[t]{3}{*}{ Diet } & FFQ $[33,63]$ & $\begin{array}{l}\text { At-home } \\
\text { paper }\end{array}$ & & $x$ & $x$ & $x$ \\
\hline & MEDAS $[103,104]$ & $\begin{array}{l}\text { On-site } \\
\text { paper }\end{array}$ & & $x$ & $x$ & $x$ \\
\hline & $\operatorname{FFL}[19,62]$ & $\begin{array}{l}\text { At-home } \\
\text { paper }\end{array}$ & & $x$ & $x$ & $x$ \\
\hline \multirow[t]{3}{*}{ Psycho-affective/worry } & PSWQ $[105,106]$ & $\begin{array}{l}\text { At-home } \\
\text { paper }\end{array}$ & & $x$ & $x$ & $x$ \\
\hline & RSQ-D [107] & $\begin{array}{l}\text { On-site } \\
\text { paper }\end{array}$ & & $x$ & $x$ & $x$ \\
\hline & STAI-G [108] & $\begin{array}{l}\text { On-site } \\
\text { paper }\end{array}$ & & $x$ & $x$ & $x$ \\
\hline \multirow[t]{2}{*}{ Quality of life } & SF-12 [109] & $\begin{array}{l}\text { On-site } \\
\text { paper }\end{array}$ & & $x$ & $x$ & $x$ \\
\hline & WHOQOL-BREF [110] & $\begin{array}{l}\text { At-home } \\
\text { paper }\end{array}$ & & $x$ & $x$ & $x$ \\
\hline $\begin{array}{l}\text { Autophagy markers from muscle } \\
\text { biopsy (optional consent) }\end{array}$ & LC3 I/II, p62 [72], EP300 [111], proteomics, metabolomics [73] & On-site & & $x$ & $x$ & \\
\hline Blood-based markers & $\begin{array}{l}\text { Polyamine levels [33], metabolomics, proinflammatory } \\
\text { biomarkers, and neurotrophin levels }\end{array}$ & On-site & & $x$ & $x$ & \\
\hline Cerebral neuroimaging markers & Brain structure, perfusion, function & On-site & & $x$ & $x$ & \\
\hline \multicolumn{7}{|l|}{ Exploratory outcomes } \\
\hline \multirow[t]{2}{*}{ Subjective cognitive function } & ECog-39, adapted [87] & $\begin{array}{l}\text { On-site } \\
\text { paper }\end{array}$ & & $x$ & $x$ & $x$ \\
\hline & MMQ, adapted [112] & $\begin{array}{l}\text { On-site } \\
\text { paper }\end{array}$ & & $x$ & $x$ & $x$ \\
\hline Cardiovascular risk factors & Blood pressure, lipid profile, glucose metabolism & On-site & & $x$ & $x$ & $x$ \\
\hline \multirow[t]{2}{*}{ Muscle function/strength* } & SPPB [113] & On-site & & $x$ & $x$ & $x$ \\
\hline & Handgrip strength & On-site & & $x$ & $x$ & $x$ \\
\hline
\end{tabular}

*Only for participants, who consented to muscle biopsy

Abbreviations: $A \beta \beta$-amyloid, APOE apolipoprotein E, BFI-10 Big Five Inventory-10, CAI Cognitive Activity Interview, ECog Everyday Cognition Scales, FKA Freiburger Fragebogen zur körperlichen Aktivität, FFL food frequency list, FFO Food Frequency Questionnaire, GDS Geriatric Depression Scale, IADL Instrumental Activities of Daily Living Scale, LEQ Lifetime Experience Questionnaire, MEDAS Mediterranean Diet Adherence Screener, MMQ Meta Memory Questionnaire, MMSE Mini-Mental State Examination, MST Mnemonic Similarity Task, MWT Mehrfachwahl-Wortschatztest, PET positron emission tomography, PSQI Pittsburgh Sleep Quality Index, PSWQ Penn State Worry Questionnaire, RSQ-D Response Styles Questionnaire-Deutsche Version, SF-12 Short Form Health Survey, SPPB Short Physical Performance Battery, STAl-G State-Trait Anxiety Inventory, SVF-78 Stressverarbeitungsfragebogen, TAP Testbatterie zur Aufmerksamkeitsprüfung, TMT Trail Making Test, VLMT Verbaler Lern-und Merkfähigkeitstest, WHOQOL-BREF World Health Organization Quality of Life 
experience, and personality traits. In addition, (d) physiological measures of brain $\mathrm{A} \beta$ status, measured using [18F] florbetaben (FBB) PET, and genotype information on apolipoprotein E (APOE) $\varepsilon 4$ status along with other learning-relevant polymorphisms, measured using genotyping of blood-derived deoxyribonucleic acid (DNA), will be obtained. Note that potential changes in demographic information and family history will be recorded throughout the trial.

\section{Outcome measures}

Assessments of study outcomes will be conducted at the baseline visit and post-intervention visit (12 months after baseline). Selected outcome measures will be assessed at the follow-up visit (18 months after baseline). Primary and secondary outcomes are summarized in Table 1. Study outcomes will be collected in accordance with standardized operational procedures (SOPs) and study assessors that are blinded to the type of intervention.

Primary endpoint: The primary endpoint of this trial is the change in memory performance between baseline visit (V1) and post-intervention visit (V2). Memory performance is operationalized by memonic discrimination ability, to be assessed by the MST [38]. Mnemonic discrimination performance is evaluated due to its established sensitivity and robustness to memory deficits associated with aging and neurodegenerative disease [48-50]. Moreover, this behavioral marker is closely tied to neural dysfunction in the hippocampal memory network $[48,49]$ and has been identified as a sensitive outcome measure in older individuals at higher risk of AD [39].

The visual memory task is available for public download (http://faculty.sites.uci.edu/starklab/mnemonic-similaritytask-mst/) with multilingual instructions. Sets of well-matched stimuli will be presented at baseline, post-intervention, and follow-up visits respectively, with a pseudorandomized order of stimuli within each set. The MST consists of two phases: During the incidental encoding phase, participants view images of everyday objects and decide on each trial, whether the object is typically found "outdoors" or "indoors." During the subsequent recognition phase, images are repeated (repetition items), randomly inter-mixed with novel images (foil items), and images that are perceptually similar to those pictures seen during the encoding phase (lure items). Participants will be asked to indicate for each trial, whether the image was "old", "new" or "similar". From the proportion of responses provided during recognition, a response bias-corrected mnemonic discrimination index will be calculated, similar to previous reports [37, 38, 48].

Secondary endpoints: Secondary outcomes include the change in memory performance (operationalized by mnemonic discrimination performance) between baseline visit (V1) and follow-up assessment (V3, 18 months after baseline). Additional secondary endpoints (see Table 1) are changes in the following outcome measures:

(a) Neuropsychological parameters on verbal and visualspatial memory, attention, executive functions, and sensorimotor speed, assessed at V1, V2, and V3

(b) Behavioral parameters of lifestyle behaviors, psycho-affective characterization and perceived quality of life, assessed at V1, V2, and V3, as well as

(c) Physiological parameters including autophagy signaling (measured in muscle biopsies), peripheral vascular parameters (measured in blood), and parameters of brain structure, perfusion, and function (measured using cerebral magnetic resonance imaging [MRI]) to be assessed at V1 and V2.

Finally, exploratory outcomes (see Table 1) of subjective cognitive function, cardiovascular risk factors, as well as muscle function and strength markers (available for a sub-sample) will be evaluated.

Using moderator analysis, we will further assess whether demographic factors (including sex), genetic phenotype (including APOE), and presence of brain pathology (including a positive brain $\mathrm{A} \beta$ status) affect outcomes of the intervention.

\section{Participant timeline}

The SmartAge trial will involve five phases for each participant: study enrollment, which included screening assessment (V0), a baseline visit (V1), a 12-month intervention period, a post-intervention visit (V2), and a follow-up visit (V3). Trial phases are described below and summarized in Fig. 1.

\section{Enrollment (VO)}

Individuals, who express interest in study participation, will undergo following screening procedure to ensure study eligibility. A standardized pre-screening interview conducted over the phone will be administered to collect information on medical and demographic data, on MRI/PET suitability, and on suitability for muscle biopsy. During this interview, the following questions will be asked to endorse the presence of SCD with associated concerns (worries), similar to previous reports and recommendations $[15,51]$. Question 1 will be "Do you feel that your cognitive performance has become worse?" (German: "Haben Sie das Gefühl, dass Ihre geistige Leistungsfähigkeit schlechter geworden ist?", possible answers: yes/no). In case of a positive answer to question 1, question 2 will be asked: "Since when do you have the feeling that your cognitive performance has gotten worse?" (German: "Seit wann hat sich ihre geistige Leistungsfähigkeit verschlechtert?"). In case the answer to question 2 is at least 6 months, question 3 will be asked: "Are you concerned about this cognitive worsening?" 


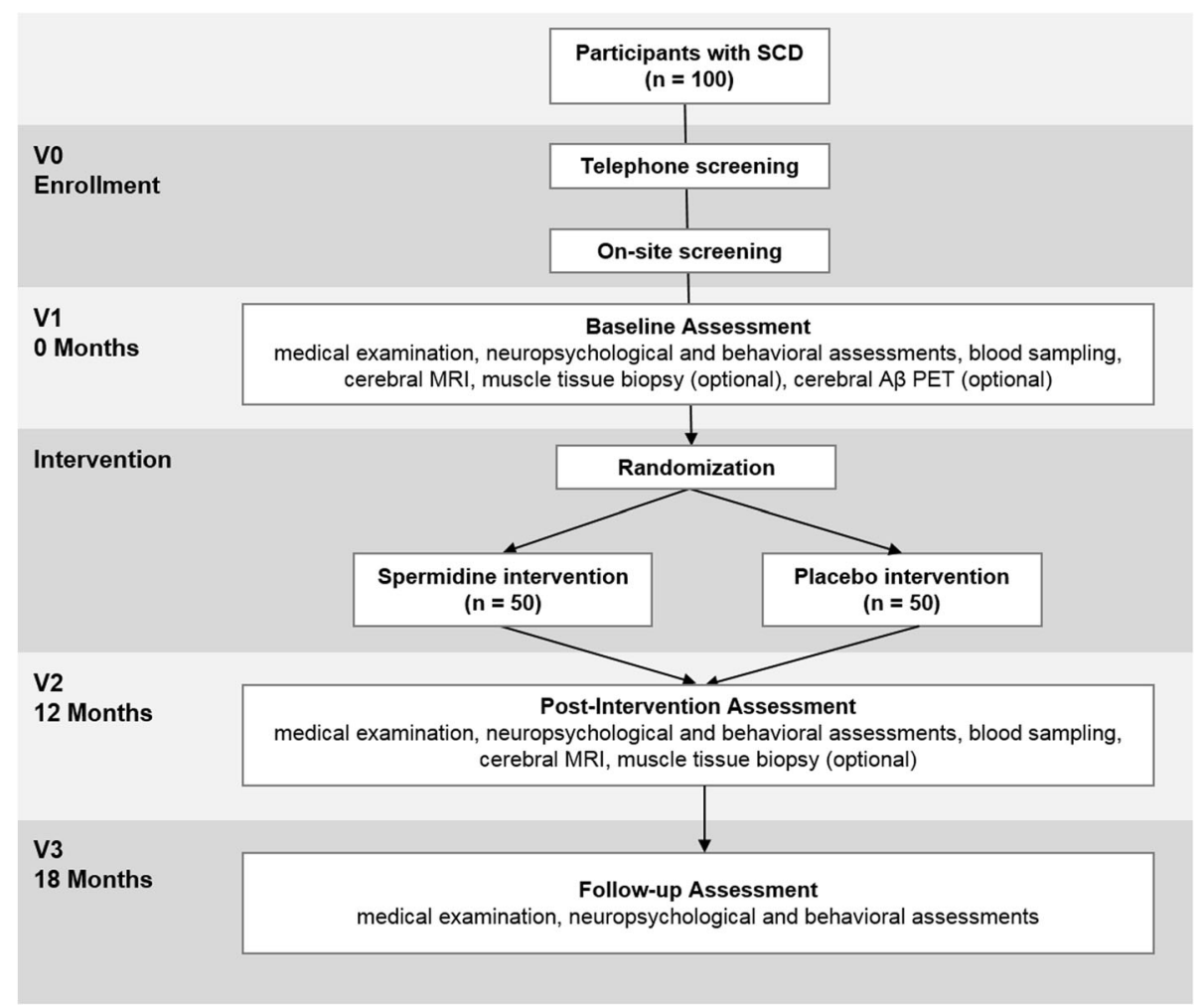

Fig. 1 SmartAge study flowchart. Abbreviations: MRI: magnetic resonance imaging; PET positron emission tomography, SCD subjective cognitive decline

(German: "Bereitet Ihnen diese Verschlechterung Sorgen?", possible answers: yes/no). In case of a positive answer to question 3, question 4 will be asked: "Would you seek or have you sought medical help due to this cognitive worsening?" (German: "Würden Sie diesbezüglich einen Arzt aufsuchen bzw. haben Sie dies bereits getan?", possible answers: yes/no). Affirmative responses to diagnostic questions $1,3,4$, and a duration of SCD for at least 6 months are mandatory for study inclusion.

Potential participants that meet inclusion criteria as evaluated during pre-screening will be invited for the on-site screening visit to the Charite - Universitätsmedizin Berlin. Each individual will receive a standardized screening assessment, including neuropsychological tests and questionnaires, to certify the absence of objective cognitive impairment and current psychiatric disorder (e.g., depression). Following measures will be used: (a) Mini-Mental State Examination (MMSE) [52] score $\geq 26$, (b) performance above - 1.5 standard deviation (SD) of age-adjusted norms in the Logical Memory II subscale total delayed recall (Story A and B) [53], and the Trail Making Test (TMT) A [54], (c) no deficits on selected items of the Instrumental Activities of Daily Living Scale (IADL) [55], and (d) a Geriatric Depression Scale (GDS) [56] score $\leq 10$. After successful completion of the on-site screening assessment, eligible participants will proceed to baseline assessment.

\section{Baseline visit (V1)}

The baseline visit will encompass a maximum of 4 days with different assessments conducted on each day. On day 1 (carried out immediately after screening, duration: approx. $5 \mathrm{~h}$ with breaks), each participant will receive a standardized medical examination that includes fasting blood sampling and physical assessments. Next, a standardized neuropsychological test battery and a questionnaire battery will be administered (Table 1). On day 2, each participant will undergo the MRI assessment (duration: approx. $2 \mathrm{~h}$ ). On day 3, muscle tissue biopsy will be carried out to determine autophagy signaling (optional consent, duration: approx. $2-3 \mathrm{~h}$, aiming for 25 participants). On day 4, a cerebral A $\beta$ PET assessment is performed (optional consent, baseline visit only, duration: approx. $2-3 \mathrm{~h}$, aiming for 50 participants). After completion of the baseline visit, participants will be randomly assigned to one intervention arm. The A $\beta$ PET measurements will in most cases be conducted after intervention has started, due to logistic reasons.

\section{Intervention period}

During the intervention, at 3 months, 6 months, and 9 months after the baseline visit (V1), telephone or on-site interviews will be scheduled with each participant to obtain information on participants' physical and mental 
well-being, trial compliance, changes in dietary habits, and current medication intake. The study assessor will also ask for possible adverse events (AEs) and serious adverse events (SAEs). At 6 months after baseline, the remaining capsules will be counted to monitor adherence to capsule intake and new capsules for the next 6 months will be provided. Moreover, participants will be asked for their subjective estimation of compliance to intervention. At the post-intervention visit (V2), capsule counting procedures and subjective estimation of compliance will be repeated.

\section{Post-intervention visit (V2)}

The post-invention visit will take place at the end of the 12-month intervention period. Assessments of the post-intervention visit will be conducted on a maximum of 3 days, to be scheduled in close temporal proximity. On day 1, the standardized screening assessment (see Table 1) is re-administered to determine possible changes in the SCD diagnostic criteria, followed by the same assessments as for the baseline visit, that is, the standardized medical examination, the standardized neuropsychological test battery and questionnaire battery. In addition, participants will be asked to provide qualitative feedback on the intervention. On day 2, the MRI assessment will be carried out and on day 3, the muscle tissue biopsy will be obtained (optional consent).

\section{Follow-up visit (V3)}

The follow-up visit will take place 18 months after baseline visit. The visit will include following assessments: standardized screening assessment, standardized medical examination without blood draw, and adapted versions of the standardized neuropsychological test battery and questionnaire battery (see Table 1). The participants will be asked to provide qualitative feedback on the intervention.

\section{Sample size}

A power calculation was conducted to estimate the number of participants required to detect a group difference in the primary outcome (i.e., mnemonic discrimination performance) at the end of the intervention. Sample size estimation was based on behavioral data obtained in a phase IIa pilot trial [37]. In this pre-study on 30 SCD participants (dropout: $n=2$ ) and a 3-month intervention period, we determined an effect size of Cohen's $d=0.65$ on the group difference in change of mnemonic discrimination performance between baseline (V1) and the end of intervention (V2). Since this is a first estimate of the effect size based on a small sample, we based our sample size estimation for the present phase IIb trial on a smaller effect size of Cohen's $d=0.6$. To demonstrate a significant effect in the primary outcome, 50 participants per group (including a 10\% dropout rate) need to be incorporated in the analysis with an unpaired-sample $t$ test (two-sided significance level $=0.05$, power $80 \%$ ). Sample size estimation was conducted using a conservative approach [57] based on an unpaired-sample $t$ test, even though the intended analysis of the primary outcome will be performed using analysis of covariance (ANCOVA) models. Case number estimation was compiled with the R package "pwr" [58].

\section{Recruitment}

Study participants will be recruited from memory clinics, neurologists, and general practitioners in private practice in Berlin and from the general population in Germany through advertisements.

\section{Methods: assignment of intervention Allocation}

Participants will be randomly assigned to the spermidine or the placebo group. A blockwise (block size of 6) randomization sequence, stratified by age $(60-70,70-$ 80 , and $80-90$ years) and sex, will be generated using a computer-based algorithm (http://www.randomization. $\mathrm{com} /$ ). Participant allocation will be performed at a 1:1 ratio by a study investigator without involvement in outcome assessments.

\section{Blinding}

This trial will be double-blind, hence, participants and study assessors will remain blinded to group assignment until after the follow-up visit (V3; last participant, last visit). Efficacy of blinding from the participants' perspective will be determined by asking each participant at post-intervention visit (V2) and follow-up visit (V3) to provide guesses of the assigned intervention condition.

\section{Methods: data collection, management, and analysis \\ Data collection methods}

Medical, neuropsychological, behavioral, and physiological data will be collected from each participant. Details on data collection procedures are provided below; time points of collection are detailed in Table 1. To ensure the standardization of data collection, all study assessors will undergo systematic training. Most data will first be recorded on paper (see Table 1) and will be entered into electronic records after each study visit with quality checks ongoing throughout the study. Quality control will be ensured through regular data monitoring.

\section{Medical history and examination}

Medical history assessment will include information on demographics, past and current medication intake, and family history. Subsequently, medical and neurological 
examinations will be conducted, including measurements of systolic and diastolic blood pressure and heart rate at rest. In addition, venous blood samples will be taken. In order to additionally test the influence of spermidine intervention on age-related sarcopenia, muscle function and muscle strength will be assessed (only of participants consented for the muscle biopsy).

\section{Neuropsychological and behavioral batteries}

The trial will include validated paper-and-pencil and computer-based neuropsychological tests as well as behavioral questionnaires (see Table 1). These instruments were selected based on their sensitivity and relevance in the study of aging and in correspondence with protocols of ongoing studies [59-61]. The neuropsychological test battery will include tests on learning and memory, executive functions, attention and working memory, as well as sensorimotor speed. The questionnaire battery will comprise measures of psycho-affective characteristics, lifestyle information (dietary habits, cognitive attainment, and physical activity), quality of life, and personality traits.

With regard to the nature of the trial, several questionnaires will be applied to collect nutritional information from each participant. Specifically, these measures will include the Food Frequency Questionnaire (FFQ), the Mediterranean Diet Adherence Screener (MEDAS), and a diet questionnaire that was previously adapted from a qualitative food frequency list (FFL) used in several German large-scale surveys [19, 62] (see Table 1). Validity and reproducibility of the FFQ are well established and based on the gold standard by Willett and colleagues [63]. The FFQ was recently applied in the study of Eisenberg and colleagues [33], indicating that this questionnaire provides meaningful estimations about the participant's polyamine intake per day.

Questionnaires will be completed on-site and at home by each participant. Trained raters will evaluate neuropsychological tests and questionnaires in accordance with existing guidelines in test or questionnaire manuals. If available, German versions of questionnaires are included. Otherwise, German translations will be acquired or provided by the DELCODE study [59].

\section{Blood sampling, genotyping, and pre-analytics}

Fasting venous blood samples will be collected to analyze various blood parameters and to conduct genotyping. Labor Berlin Charité Vivantes $\mathrm{GmbH}$ will perform analyses of blood samples for safety parameters and research parameters, including glucose metabolism and lipid profile, in accordance with established SOPs. Polyamine levels (spermidine, spermine, and putrescine), metabolomics, proinflammatory biomarkers, and neurotrophin levels in whole blood, serum and plasma samples will be analyzed by the Institute of Molecular Biosciences, University of
Graz, Austria. In addition, analysis of intracellular proteins with focus on nutrient signaling, metabolic regulation, and membrane-bound cellular markers of aging will be measured in peripheral blood mononuclear cells (PBMCs) extracted from whole blood [64]. In isolated leukocytes obtained from blood samples, acetylation levels and autophagy flux will be analyzed in collaboration with the INSERM U1138, Centre de Recherche des Cordeliers, Paris, France. Genetic analyses will be conducted by the Department of Psychiatry, Martin Luther University, Halle-Wittenberg, Germany.

Preprocessing and intermediate storage of blood samples will be performed at the Charité NeuroCure - Labs and at the NeuroCure Clinical Research Center, Charité - Universitätsmedizin Berlin. Blood samples for Labor Berlin Charité Vivantes $\mathrm{GmbH}$ will be shipped immediately. All other samples will be stored at $-80^{\circ} \mathrm{C}$ or at $4^{\circ}$ $\mathrm{C}$ in phosphate-buffered saline and sodium azide until shipment for further processing and analyses. NeuroHub biomarker management platform and LabVantage software will guarantee standardized workflows, documentation, and monitoring of pre-analytics including processing as well as storage as described previously [36, 65].

\section{Magnetic resonance imaging}

The MRI examination will take place on a 3-T scanner (Tim Trio, Siemens, Erlangen, Germany) at the Berlin Center for Advanced Neuroimaging (BCAN, Charité - Universitätsmedizin Berlin). The SmartAge MRI protocol will include structural and functional sequences (see Table 2). For structural imaging, a T1-weighted three-dimensional magnetization-prepared rapid acquisition gradient echo (MPRAGE) sequence, a Fluid Attenuated Inversion Recovery (FLAIR) sequence, Diffusion Tensor Imaging (DTI), and a high-resolution T2-weighted structural scan will be acquired perpendicular to the longitudinal axis of the hippocampus. The protocol will further include the following functional sequences: a blood-oxygen-level-dependent (BOLD) functional echo planar imaging (EPI), as assessed during rest (resting-state functional MRI) and during task (task-related functional MRI), and pseudo-continuous arterial spin labeling (pCASL) for cerebral blood flow (CBF) quantification during rest $[66,67]$.

Functional MRI will include an associative face-name memory task, adapted and modified from a previous publication [68]. During the scanning session, the participants will learn 24 face-name pairs (encoding phase), which have to be correctly identified in a subsequent recognition phase. For details on this memory task, please refer to Sperling and colleagues $[69,70]$.

All MRI scans will undergo quality checks and will be evaluated quantitatively using state-of-the-art brain MRI software packages and toolboxes implemented in Statistical 
Table 2 Neuroimaging data acquisition parameters

\begin{tabular}{ll}
\hline Sequence & Main parameters [orientation, TR/TE/TI, FOV, slices, voxel size] \\
\hline $\begin{array}{l}\text { Structural sequences } \\
\text { T1 MPRAGE }\end{array}$ & Sagittal, TR/TE $/ T$ I $=1900 / 2.52 / 900 \mathrm{~ms}, 256 \times 256 \mathrm{~mm}^{2}, 192$ slices, $1.0 \times 1.0 \times 1.0 \mathrm{~mm}^{3}$ \\
FLAIR & Axial, TR/TE $=11,000 / 97 \mathrm{~ms}, 230 \times 230 \mathrm{~mm}^{2}, 50$ slices, $1.2 \times 1.2 \times 2.5 \mathrm{~mm}^{3}$ \\
DTI & Axial, TR/TE $=7500 / 86 \mathrm{~ms}, 220 \times 220 \mathrm{~mm}^{2}, 61$ slices, $2.3 \times 2.3 \times 2.3 \mathrm{~mm}^{3}, 64$ directions $(b=1000)$ \\
High-resolution hippocampus TSE & Coronar, TR/TE $=8020 / 48 \mathrm{~ms}, 150 \times 150 \mathrm{~mm}^{2}, 24$ slices, $0.4 \times 0.4 \times 2.0 \mathrm{~mm}^{3}$ \\
Functional sequences & \\
Resting-state fMRI & Axial, TR/TE $=2300 / 30 \mathrm{~ms}, 192 \times 192 \mathrm{~mm}^{2}, 34$ slices, $3.0 \times 3.0 \times 4.0 \mathrm{~mm}^{3}$ \\
Task-related fMRI & Axial, TR/TE $=2000 / 30 \mathrm{~ms}, 192 \times 192 \mathrm{~mm}^{2}, 32$ slices, $3.0 \times 3.0 \times 3.0 \mathrm{~mm}^{3}$ \\
PCASL & Axial, TR/TE $=4300 / 19 \mathrm{~ms}, 192 \times 192 \mathrm{~mm}^{2}, 22$ slices, $3.0 \times 3.0 \times 5.0 \mathrm{~mm}^{3}, \mathrm{LD} / \mathrm{PLD}=1.5 / 1.5 \mathrm{~s}$ \\
\hline
\end{tabular}

Abbreviations: DTI diffusion tensor imaging, FLAIR fluid-attenuated inversion recovery, $f M R I$ functional magnetic resonance imaging, FOV field of view, $L D$ labeling duration, MPRAGE magnetization-prepared rapid acquisition gradient echo, $p C A S L$ pseudo-continuous arterial spin labeling, PLD post-label delay, TE echo time, $T I$ inversion time, TR repetition time, TSE turbo spin echo

Parametric Mapping (SPM, Wellcome Department of Imaging Neuroscience), FSL (FMRIB Software Library, Oxford, UK), and FreeSurfer (Martinos Center for Biomedical Imaging, Massachusetts General Hospital, Boston, USA). Structural MRI scans will be used to examine the integrity of cerebral gray and white matter tissues, including assessments of volume, thickness, microstructure, and high-resolution volumetric quantification of medial-temporal structures [71]. Functional scans will be analyzed to assess brain activation patterns during the associative memory task as well as CBF maps and functional connectivity at rest.

Muscle tissue biopsy and muscle function (optional consent) Muscle tissue biopsy will be performed at the Clinical Research Unit, Berlin Institute of Health (BIH, Charité Universitätsmedizin Berlin). In total, 200-400 mg muscle tissue will be collected from the participant's thigh (Musculus vastus lateralis). For this purpose, local anesthesia with lidocaine $1 \%$ without epinephrine will be administered. Subsequently, a skin incision (3-4 mm) will be made and the muscle tissue will be obtained by repeated needle biopsies (Bergström needle). Participants are asked to fast prior to the procedure for at least $8 \mathrm{~h}$. After 12-month intervention time (V2) a second muscle tissue biopsy will be carried out at the same leg close to the first puncture site. Biopsy tissue processing will include snap freezing in liquid nitrogen and paraffin embedding. Samples will be stored at $-80^{\circ} \mathrm{C}$ until analysis.

Potential changes in muscle autophagy markers in response to spermidine intervention will be quantified by immunohistochemical analysis of autophagic flux and autophagic capacity [72] as well as by acetylproteome analysis as an upstream regulator of autophagy [73].

In addition, non-invasive measurements of muscle function and muscle strength will be assessed during medical examination from all participants who consented to muscle biopsy, to determine age-related sarcopenia. For this purpose, the following standardized measurements of sarcopenia will be administered: Short Physical Performance Battery (SPPB) [74, 75], and a handgrip strength test [75]. The SPPB is a composite measure and will include 4-m gait speed, balance, and chair stand tests.

\section{Positron emission tomography (optional consent)}

Quantification of brain $A \beta$ status is carried out using PET and the approved ligand FBB (Neuraceq ${ }^{\text {ins }}$; Life Molecular Imaging (LMI)). The FBB PET images will be acquired using the PET/MR hybrid system (Siemens Biograph mMR) of the Institute of Diagnostic and Interventional Radiology and Nuclear Medicine, Charité - Universitätsmedizin Berlin. For data acquisition, 260-300 MBq of FBB PET tracer will be administered intravenously. Participants will undergo a static scan at 90-110 min after injection and images will be consistently reconstructed according to the current procedure guideline on brain PET imaging of the German Society of Nuclear Medicine [76].

The FBB PET scans will be processed using an automated pipeline based on the routines of the SPM software package, implemented in a MATLAB environment (Mathworks, Inc., Nattick, MA, USA). For each PET scan, intra-PET motion correction, construction of static standardized uptake value (SUV) images, and correction for partial volume effects using the Müller-Gärtner method [77] as implemented in the PETPVE12 toolbox [78] will be performed. Intensity scaling using the cerebellar cortex as reference region [79] will be applied to obtain standardized uptake value ratio (SUVr) images. Neocortical $A \beta$-plaques burden will be evaluated as the average FBB SUVr within a predefined composite of cortical regions-of-interest [76]. In addition, exploratory voxel-by-voxel analyses will be performed on the FBB SUVr images.

\section{Data management and monitoring}

Documentation using a paper-based case report form (CRF) will be implemented. To certify excellent data 
quality, a good clinical practice (GCP) monitoring will be held on a regular basis. The SmartAge research team will be responsible for data management under the guidance of the principal investigator (AF). All CRF data will be entered into an electronic database with following quality control procedures: (a) double scoring and double entry of data points in the paper-based records and electronic records and (b) frequency distribution checks of outcome measures (not stratified by intervention group) to identify questionable data points.

\section{Adverse events monitoring and reporting}

The occurrence of AEs and SAEs will be constantly monitored throughout the SmartAge trial. Participants will be instructed to immediately contact the research team in case of any self-noticed health changes or unexpected medical care visits. In addition, participants will receive a study pass, which informs about participation in the SmartAge trial and provides contact information in case of an SAE/hospitalization. All AEs and SAEs will be reported to and documented by the responsible study physician (SAEs within $24 \mathrm{~h}$ ).

In general, the risk of health damage due to spermidine supplementation can be expected to be minimal, based on a prior interventional report [35] and our safety study [36]. Participants will be informed about all possible risks and can withdraw consent at any time without providing reasons. The expected "dropout" rate will be balanced in advance by the number of participants.

In case an SAE occurs, the study physician will first make an assessment as to whether or not a causal relationship with the intake of the investigational supplement is considered possible. Since this is a double-blinded trial, the assessment will be done without knowledge of group affiliation (spermidine and placebo). Emergency unblinding is possible, if the decision on follow-up medical treatment may depend on the participant's allocated intervention during the trial. If more than three of the enrolled participants suffer from SAEs that are likely to be associated with spermidine intake (as assessed by the study physician), the SmartAge trial will be discontinued. All SAEs (whether or not related to the intervention) and all relevant pseudonymized documentation related to the SAE will be documented in the SAE report form, dated and signed by the principal investigator and included in the CRF documentation.

\section{Statistical methods}

Statistical analyses of the primary outcome and secondary outcomes will be specified in the statistical analysis plan, to be written and registered before breaking the blind of study investigators. Statistical analyses of the primary outcome will be conducted by a designated statistician. Statistical analyses of secondary outcomes and additional exploratory analyses will be carried out by study investigators.

The primary outcome will be analyzed using an "intention to treat" (ITT) approach, consisting of all participants randomized into the trial, regardless of length of intervention. Subsequently, a "per protocol" analysis is carried out, including only those participants, who finished the 12-month intervention period. We will assess the between-group difference in the change of memory performance, operationalized by mnemonic discrimination performance, between baseline (V1) and the end of intervention (V2). Statistical analysis will be performed using an ANCOVA model with the change in memory performance (V2-V1) as dependent variable, intervention group as independent variable, and baseline memory performance as well as age as co-variates. Analyses of secondary endpoints will be conducted using comparable statistical methods. For example, analysis of change in memory performance between baseline (V1) and follow-up assessment (V3) will be carried out by means of ANCOVA. In this model, change in memory performance (V3-V1) will represent the dependent variable, with intervention group as the independent variable and baseline scores and age inserted as covariate.

In case of missing primary endpoints, the primary analysis will be done by using multiple imputation methods. It will further be investigated whether demographic or biological factors are associated with primary and secondary endpoints and / or modulate the response to the intervention, by integrating these variables into statistical models as covariates (or as interactive term with the intervention group). The main hypothesis is tested at a two-sided significance level of alpha $=0.05$, using the ITT data set with multiple imputation.

\section{Dissemination policy}

Results of the SmartAge trial will be distributed to scientific researchers and health-care professionals using peer reviewed journals and presentations (oral and written) at national and international scientific conferences. Publications will follow international recommendations of "Uniform Requirements for Manuscripts Submitted to Biomedical Journals" (http://www.icmje.org/recommendations/). Results will also be made available for scientific and lay audiences on the ClinicalTrials.gov website (Registered in ClinicalTrials.gov with the Identifier NCT03094546). In addition, we will transmit findings to the general population and key stakeholders using media coverage, such as newspaper articles and radio/television interviews.

\section{Discussion}

This is the first randomized controlled phase IIb trial to determine potential beneficial impacts of a 12-month 
nutritional spermidine supplementation on memory performance in older individuals at risk for the development of AD. In addition, we will assess memory performance at 18 months and outcome measures of other neurocognitive domains as well as behavioral and physiological parameters to evaluate further benefits of the intervention.

The target group of the SmartAge trial comprises cognitively unimpaired older individuals with SCD. Given the fact that this population is at higher risk of objective cognitive decline and clinical progression $[7,8,15]$, it is the key goal of this study to contribute to the development of effective prevention strategies. Our initial short-term (3 months) phase IIa trial demonstrated that spermidine supplementation is an easy-to-use, safe, and well-tolerated intervention [36]. Based on existing findings in animals and in humans [30, 32, 37], oral spermidine intake may be expected to protect memory performance and, as a consequence, favor perceived quality of life in older individuals with SCD.

There are several caveats that are important to acknowledge. Subjective cognitive decline is a heterogeneous condition that likely includes different etiologies as well as individuals, who will experience objective cognitive decline, while others remain stable for a long period of time. Although significant progression has been made to establish diagnostic criteria for SCD, there is no universal standard for the operationalization of SCD in clinical trials [80]. We have followed the existing guidelines and recommendations by the international SCD-I working group for studies on SCD [15] and examined other major SCD characterization cohort studies [81]. Likewise, cutoff scores for cognitive abilities are not strictly defined in the field, with cognitive deficits varying between 1 and 2 standard deviations below the normative mean [82]. Based on the literature review, we chose to use a 1.5 standard deviations cutoff to define cognitive abnormality, in line with other major SCD studies in the field [59]. Therefore, conceivably some of the recruited participants in this trial will be on the lower spectrum of cognitive abilities, close to mild cognitive impairment. Strengths of using a "more liberal" cognitive threshold include increased average rates of cognitive decline over the intervention period. We have further enriched our sample characterization through $\mathrm{AD}$ biomarkers, such as brain $\mathrm{A} \beta$ status (available for a sub-sample) and genetic risk factors. On the basis of this information, moderator analyses will be performed to estimate the effect of these $\mathrm{AD}$ variables on the intervention outcomes.

Other limitations of this phase IIb trial include the time period of intervention, which is still relatively short given the slow evolution of $\mathrm{AD}$ pathogenic processes in non-demented older individuals [83], and the restricted number of participants. Larger multi-center phase III trials with 1000-2000 participants and trial durations of 1.5-2 years commonly select clinical outcome measures, which are however less sensitive [84]. We deliberately chose a highly sensitive performance-based outcome measure, given our relatively short intervention time and manageable number of subjects. Although we recognize the importance of larger sample sizes, we remain optimistic that any subtle cognitive changes in our at-risk population will be detected based on our previous phase IIa trial [37]. Lastly, it is important to highlight that a multi-center trial implementation was not financially attainable. Pending the positive results of this trial, public funding for a phase III trial will be applied for, to move this intervention into clinical routine.

Overall, the SmartAge trial aims to contribute to the establishment of an effective and well-tolerable nutrition intervention to promote brain and cognitive health in older individuals at higher risk of dementia. A positive outcome with regard to memory performance in the spermidine-treated group may initiate a large multi-center phase III trial with a profound impact on public health, patients with SCD, and their families.

\section{Trial status}

Recruitment of participants started in January 2017 and is expected to run until March 2019. The last follow-up is scheduled for September 2020.

\section{Abbreviations}

AD: Alzheimer's disease; AE: Adverse event; ANCOVA: Analysis of covariance; APOE: Apolipoprotein E; A $\beta$ : $\beta$-Amyloid; BCAN: Berlin Center for Advanced Neuroimaging; BFI-10: Big five inventory-10; BOLD: Blood-oxygen-leveldependent; bw: Body weight; CAl: Cognitive Activity Interview; CBF: Cerebral blood flow; CRF: Case report form; DNA: Deoxyribonucleic acid; DSMIV: Diagnostic and Statistical Manual of Mental Disorders, 4th Edition; DTI: Diffusion Tensor Imaging; ECog: Everyday Cognition Scales; EPI: Echo planar imaging; FBB: Florbetaben; FFL: Food frequency list; FFQ: Food Frequency Questionnaire; FKA: Freiburger Fragebogen zur körperlichen Aktivität; FLAIR: Fluid-attenuated inversion recovery; fMRI: Functional magnetic resonance imaging; GCP: Good clinical practice; GDS: Geriatric Depression Scale; IADL: Instrumental Activities of Daily Living Scale; ITT: Intention to treat; LEQ: Lifetime Experience Questionnaire; MCl: Mild cognitive impairment; MEDAS: Mediterranean Diet Adherence Screener; MMSE: Mini-Mental State Examination; MPRAGE: Magnetization-prepared rapid acquisition gradient echo; MRI: Magnetic resonance imaging; MST: Mnemonic similarity task; MWT: Mehrfachwahl-Wortschatztest; NOAEL: No observed adverse effects level; PBMCs: Peripheral blood mononuclear cells; pCASL: Pseudo-continuous arterial spin labeling; PET: Positron emission tomography; PSQI: Pittsburgh Sleep Quality Index; PSWQ: Penn State Worry Questionnaire; RSQ-D: Response Styles Questionnaire-Deutsche Version; SAE: Serious adverse event; SCD: Subjective cognitive decline; SD: Standard deviation; SF-12: Short Form Health Survey; SOP: Standardized operational procedure; SPM: Statistical Parametric Mapping; SPPB: Short Physical Performance Battery; STAI-G: State-Trait Anxiety Inventory; SUV: Standardized uptake value; SUVr: Standardized uptake value ratio; SVF78: Stressverarbeitungsfragebogen; TMT: Trail Making Test; VLMT: Verbaler Lern-und Merkfähigkeitstest; WHOQOL: World Health Organization Quality of Life

\section{Protocol amendments}

Any substantial amendment to the study protocol will be submitted to the institutional Ethics Committee for review and approval.

\section{Consent or assent}

A member of the investigational team (study coordinator or study assessor)

will collect written informed consent during study enrollment after having 
reviewed the participant information sheet, participant's questions, and study inclusion and exclusion criteria.

\section{Confidentiality}

The collected data will be treated as confidential. Direct access to personal information and source data documentation will only be given to study monitors, study assessors, and the research team.

\section{Funding}

Funding for this trial is provided by the Bundesministerium für Bildung und Forschung (SMARTAGE, FKZ 01GQ1420B), the Hans Gerhard Creutzfeldt scholarship (FKZ CSB II, 01 EO1301 TP T2), and the Deutsche Forschungsgemeinschaft (DFG, EXC 257 NeuroCure). For the applied PET measurements, the approved ligand FBB (Neuraceq ${ }^{\mathrm{TM}}$ ) is provided free of charge by Life Molecular Imaging (LMI). Frank Madeo is grateful to BioTechMed-Graz for the flagship project "EPIAge", to the Austrian Science Fund FWF (Austria) for grants, P29262, P29203, P27893, and SFB Lipotox' (F3012), as well as to BMWFW and the Karl-Franzens University for grants 'Unkonventionelle Forschung' and flysleep (80.109/0001 - WFN/3b/2015). Sponsor: Charité - Universitätsmedizin Berlin

\section{Availability of data and materials}

Anonymized data will be made available to the scientific community upon request.

\section{Authors' contributions}

AF led the trial conceptualization and design of this trial and supervised its implementation. MW established the design of the trial and led the drafting of the study protocol. MW and CS managed the trial, budget, and staff. CS and GB implemented and conducted the trial. MW, GB, and UK designed the neuropsychological test battery and questionnaire battery. $\mathrm{RB}$ and $\mathrm{CL}$ were responsible for the approval and implementation of the PET protocol. SH and CS participated in the design and implementation of the MRI protocol. TK contributed to the drafting of the study protocol and participated in trial implementation. SM, UK, and KM participated in the design of the protocol and/or study assessments. SM, MM, and EM participated in the implementation and/or conductance of the laboratory analyses. UG developed the statistical analysis plan. SSi, SSt, and FM led the development of the nutrition intervention. MW, CS, GB, and NH drafted this manuscript based on the study protocol. All other authors read and revised the original draft and consecutive versions of the manuscript. All authors read and approved the final version of the protocol paper.

\section{Ethics approval and consent to participate}

The study protocol, participant information sheet, and participant informed consent were submitted for ethical review and have received approval from the Ethics Committee of the Charité - Universitätsmedizin, Berlin, Germany (EA1/ 250 /16, date of first approval: 13.10.2016). The FBB PET measurements were approved by the Federal Radiation Protection Authority (Bundesamt für Strahlenschutz (BfS)) Salzgitter Germany (Z5 - 22461/2 - 2016-010, date of approval: 17.07.2017). All procedures conducted during the SmartAge trial will be carried out in compliance with the Declaration of Helsinki.

\section{Consent for publication}

\section{Not applicable}

\section{Competing interests}

Slaven Stekovic, Stephan J. Sigrist, and Frank Madeo have a financial interest in TLL. All other authors declare that they have no competing interests.

\section{Publisher's Note}

Springer Nature remains neutral with regard to jurisdictional claims in published maps and institutional affiliations.

\section{Author details}

${ }^{1}$ Charité - Universitätsmedizin Berlin, Corporate Member of Freie Universität Berlin, Humboldt-Universität zu Berlin, and Berlin Institute of Health, Klinik und Hochschulambulanz für Neurologie, Berlin, Germany. ${ }^{2}$ Charité Universitätsmedizin Berlin, Corporate Member of Freie Universität Berlin, Humboldt-Universität zu Berlin, and Berlin Institute of Health, NeuroCure Clinical Research Center, Berlin, Germany. ${ }^{3}$ Charité - Universitätsmedizin
Berlin, Corporate Member of Freie Universität Berlin, Humboldt-Universität zu Berlin, and Berlin Institute of Health, Center for Stroke Research Berlin, Berlin, Germany. ${ }^{4}$ German Center for Neurodegenerative Diseases (DZNE), Dresden, Germany. ${ }^{5}$ Charité - Universitätsmedizin Berlin, Corporate Member of Freie Universität Berlin, Humboldt-Universität zu Berlin, and Berlin Institute of Health, Department of Nuclear Medicine, Berlin, Germany. ${ }^{6}$ University Hospital Hamburg-Eppendorf, Department of Diagnostic and Interventional Radiology and Nuclear Medicine, Hamburg, Germany. ${ }^{7}$ Douglas Mental Health University Institute, Studies on Prevention of Alzheimer's Disease (StOP-AD) Centre, Montreal, Quebec, Canada. ${ }^{8}$ Department of Psychiatry, McGill University, Montreal, Quebec, Canada. ${ }^{9}$ Charité - Universitätsmedizin Berlin, Corporate Member of Freie Universität Berlin, Humboldt-Universität zu Berlin, and Berlin Institute of Health, Berlin Center for Advanced Neuroimaging, Berlin, Germany. ${ }^{10}$ Bernstein Center for Computational Neuroscience, Berlin, Germany. ${ }^{11}$ Institute for Biology/Genetics, Freie Universität Berlin, Berlin, Germany. ${ }^{12}$ Charité - Universitätsmedizin Berlin, Corporate Member of Freie Universität Berlin, Humboldt-Universität zu Berlin, and Berlin Institute of Health, Department of Endocrinology \& Metabolism, Berlin, Germany. ${ }^{13}$ Charité-Center for Cardiovascular Research (CCR), Berlin, Germany. ${ }^{14}$ German Center for Neurodegenerative Diseases (DZNE), Berlin, Germany. ${ }^{15}$ Charité - Universitätsmedizin Berlin, Corporate Member of Freie Universität Berlin, Humboldt-Universität zu Berlin, and Berlin Institute of Health, Institute of Biometry and Clinical Epidemiology, Berlin, Germany. ${ }^{16}$ Berlin Institute of Health $(\mathrm{BIH})$, Berlin, Germany. ${ }^{17}$ Institute of Molecular Biosciences, University of Graz, NAWI Graz, Graz, Austria. ${ }^{18}$ BioTechMed, Graz, Austria. ${ }^{19}$ Department of Neurology, University Medicine Greifswald, Greifswald, Germany. ${ }^{20}$ German Center for Neurodegenerative Diseases (DZNE), Rostock/Greifswald, Rostock, Germany.

\section{Received: 1 October 2018 Accepted: 20 March 2019}

Published online: 01 May 2019

\section{References}

1. United Nations DoEaSA, Population Division;: World Population Ageing. New York: United Nations; 2015.

2. Prince M, Wimo A, Guerchet M, Ali G, Wu Y, Prina M. World Alzheimer report 2015-the global impact of dementia: an analysis of prevalence, incidence, cost and trends. London; 2015.

3. Norton $\mathrm{S}$, Matthews FE, Barnes DE, Yaffe K, Brayne C. Potential for primary prevention of Alzheimer's disease: an analysis of population-based data. Lancet Neurol. 2014;13:788-94.

4. Sperling RA, Aisen PS, Beckett LA, Bennett DA, Craft S, Fagan AM, Iwatsubo $T$, Jack CR Jr, Kaye J, Montine TJ, et al. Toward defining the preclinical stages of Alzheimer's disease: recommendations from the National Institute on Aging-Alzheimer's Association workgroups on diagnostic guidelines for Alzheimer's disease. Alzheimer's Dementia. 2011;7:280-92.

5. Jack CR Jr, Knopman DS, Jagust WJ, Shaw LM, Aisen PS, Weiner MW, Petersen RC, Trojanowski JQ. Hypothetical model of dynamic biomarkers of the Alzheimer's pathological cascade. Lancet Neurol. 2010;9:119-28.

6. Jessen F, Wolfsgruber S, Wiese B, Bickel H, Mosch E, Kaduszkiewicz H, Pentzek M, Riedel-Heller SG, Luck T, Fuchs A, et al. AD dementia risk in late $\mathrm{MCl}$, in early $\mathrm{MCl}$, and in subjective memory impairment. Alzheimers Dement. 2014;10:76-83.

7. Mitchell AJ, Beaumont H, Ferguson D, Yadegarfar M, Stubbs B. Risk of dementia and mild cognitive impairment in older people with subjective memory complaints: meta-analysis. Acta Psychiatr Scand. 2014;130:439-51.

8. van Harten AC, Mielke MM, Swenson-Dravis DM, Hagen CE, Edwards KK, Roberts RO, Geda YE, Knopman DS, Petersen RC. Subjective cognitive decline and risk of MCl: the Mayo Clinic study of aging. Neurology. 2018;91: e300-12.

9. Snitz BE, Wang T, Cloonan YK, Jacobsen E, Chang CH, Hughes TF, Kamboh MI, Ganguli M. Risk of progression from subjective cognitive decline to mild cognitive impairment: the role of study setting. Alzheimers Dement. 2018; 14:734-42.

10. Amariglio RE, Becker JA, Carmasin J, Wadsworth $L P$, Lorius N, Sullivan $C$, Maye JE, Gidicsin C, Pepin LC, Sperling RA, et al. Subjective cognitive complaints and amyloid burden in cognitively normal older individuals. Neuropsychologia. 2012;50:2880-6.

11. Jessen F, Feyen L, Freymann K, Tepest R, Maier W, Heun R, Schild HH, Scheef $\mathrm{L}$. Volume reduction of the entorhinal cortex in subjective memory impairment. Neurobiol Aging. 2006;27:1751-6. 
12. Cherbuin N, Sargent-Cox K, Easteal S, Sachdev P, Anstey KJ. Hippocampal atrophy is associated with subjective memory decline: the PATH through life study. Am J Geriatr Psychiatry. 2015;23:446-55.

13. Wirth M, Bejanin A, La Joie R, Arenaza-Urquijo EM, Gonneaud J, Landeau B, Perrotin A, Mezenge F, de La Sayette V, Desgranges B, Chetelat G. Regional patterns of gray matter volume, hypometabolism, and beta-amyloid in groups at risk of Alzheimer's disease. Neurobiol Aging. 2018;63:140-51.

14. Erk S, Spottke A, Meisen A, Wagner M, Walter H, Jessen F. Evidence of neuronal compensation during episodic memory in subjective memory impairment. Arch Gen Psychiatry. 2011;68:845-52.

15. Jessen F, Amariglio RE, van Boxtel M, Breteler M, Ceccaldi M, Chetelat G, Dubois B, Dufouil C, Ellis KA, van der Flier WM, et al: A conceptual framework for research on subjective cognitive decline in preclinical Alzheimer's disease. Alzheimers Dement. 2014;10:844-52.

16. Scheef L, Spottke A, Daerr M, Joe A, Striepens N, Kolsch H, Popp J, Daamen M, Gorris D, Heneka MT, et al. Glucose metabolism, gray matter structure, and memory decline in subjective memory impairment. Neurology. 2012;79:1332-9.

17. Smart CM, Karr JE, Areshenkoff CN, Rabin LA, Hudon C, Gates N, Ali Jl, Arenaza-Urquijo EM, Buckley RF, Chetelat G, et al. Non-pharmacologic interventions for older adults with subjective cognitive decline: systematic review, meta-analysis, and preliminary recommendations. Neuropsychol Rev. 2017;27:245-57

18. Wirth M, Haase CM, Villeneuve S, Vogel J, Jagust WJ. Neuroprotective pathways: lifestyle activity, brain pathology, and cognition in cognitively normal older adults. Neurobiol Aging. 2014;35:1873-82.

19. Floel A, Witte AV, Lohmann H, Wersching H, Ringelstein EB, Berger K, Knecht S. Lifestyle and memory in the elderly. Neuroepidemiology. 2008;31:39-47.

20. Mattson MP. Lifelong brain health is a lifelong challenge: from evolutionary principles to empirical evidence. Ageing Res Rev. 2015;20:37-45.

21. Arenaza-Urquijo EM, Wirth M, Chetelat G. Cognitive reserve and lifestyle: moving towards preclinical Alzheimer's disease. Front Aging Neurosci. 2015;7:134

22. Schwarz C, Wirth M, Gerischer L, Grittner U, Witte AV, Kobe T, Floel A. Effects of Omega-3 fatty acids on resting cerebral perfusion in patients with mild cognitive impairment: a randomized controlled trial. J Prev Alzheimers Dis. 2018;5:26-30.

23. Witte AV, Fobker $M$, Gellner $\mathrm{R}$, Knecht $\mathrm{S}$, Floel A. Caloric restriction improves memory in elderly humans. Proc Natl Acad Sci U S A. 2009;106:1255-60.

24. Prehn K, Jumpertz von Schwartzenberg R, Mai K, Zeitz U, Witte AV, Hampel D, Szela AM, Fabian S, Grittner U, Spranger J, Floel A. Caloric restriction in older adults-differential effects of weight loss and reduced weight on brain structure and function. Cereb Cortex. 2017;27:1765-78.

25. Eisenberg T, Knauer H, Schauer A, Buttner S, Ruckenstuhl C, Carmona-Gutierrez D, Ring J, Schroeder S, Magnes C, Antonacci L, et al. Induction of autophagy by spermidine promotes longevity. Nat Cell Biol. 2009;11:1305-14.

26. Buttner S, Broeskamp F, Sommer C, Markaki M, Habernig L, AlavianGhavanini A, Carmona-Gutierrez D, Eisenberg T, Michael E, Kroemer G, et al. Spermidine protects against alpha-synuclein neurotoxicity. Cell Cycle. 2014; 13:3903-8.

27. Minois N, Carmona-Gutierrez D, Madeo F. Polyamines in aging and disease. Aging (Albany NY). 2011;3:716-32.

28. Tiboldi A, Lentini A, Provenzano B, Tabolacci C, Hoger H, Beninati S, Lubec G. Hippocampal polyamine levels and transglutaminase activity are paralleling spatial memory retrieval in the C57BL/6J mouse. Hippocampus. 2012;22:1068-74

29. Liu P, Gupta N, Jing Y, Zhang H. Age-related changes in polyamines in memory-associated brain structures in rats. Neuroscience. 2008;155:789-96.

30. Gupta VK, Scheunemann L, Eisenberg T, Mertel S, Bhukel A, Koemans TS, Kramer JM, Liu KS, Schroeder S, Stunnenberg HG, et al. Restoring polyamines protects from age-induced memory impairment in an autophagy-dependent manner. Nat Neurosci. 2013;16:1453-60.

31. Madeo F, Eisenberg T, Pietrocola F, Kroemer G. Spermidine in health and disease. Science. 2018;359(6374): eaan2788.

32. Gupta VK, Pech U, Bhukel A, Fulterer A, Ender A, Mauermann SF, Andlauer TF, Antwi-Adjei E, Beuschel C, Thriene K, et al. Spermidine suppresses ageassociated memory impairment by preventing adverse increase of presynaptic active zone size and release. PLoS Biol. 2016;14:e1002563.

33. Eisenberg T, Abdellatif M, Schroeder S, Primessnig U, Stekovic S, Pendl T, Harger A, Schipke J, Zimmermann A, Schmidt A, et al. Cardioprotection and lifespan extension by the natural polyamine spermidine. Nat Med. 2016;22:1428-38.

34. Soda K. Polyamine intake, dietary pattern, and cardiovascular disease. Med Hypotheses. 2010;75:299-301.
35. Soda K, Kano Y, Sakuragi M, Takao K, Lefor A, Konishi F. Long-term oral polyamine intake increases blood polyamine concentrations. J Nutr Sci Vitaminol (Tokyo). 2009;55:361-6.

36. Schwarz C, Stekovic S, Wirth M, Benson G, Royer P, Sigrist SJ, Pieber T, Dammbrueck C, Magnes C, Eisenberg T, et al. Safety and tolerability of spermidine supplementation in mice and older adults with subjective cognitive decline. Aging (Albany NY). 2018;10:19-33.

37. Wirth M, Benson G, Schwarz C, Kobe T, Grittner U, Schmitz D, Sigrist SJ, Bohlken J, Stekovic S, Madeo F, Floel A. The effect of spermidine on memory performance in older adults at risk for dementia: a randomized controlled trial. Cortex. 2018;109:181-8.

38. Stark SM, Yassa MA, Lacy JW, Stark CE. A task to assess behavioral pattern separation (BPS) in humans: data from healthy aging and mild cognitive impairment. Neuropsychologia. 2013;51:2442-9.

39. Bakker A, Krauss GL, Albert MS, Speck CL, Jones LR, Stark CE, Yassa MA, Bassett SS, Shelton AL, Gallagher M. Reduction of hippocampal hyperactivity improves cognition in amnestic mild cognitive impairment. Neuron. 2012; 74:467-74.

40. Staudacher HM, Irving PM, Lomer MCE, Whelan K. The challenges of control groups, placebos and blinding in clinical trials of dietary interventions. Proc Nutr Soc. 2017;76:203-12.

41. American Psychiatric Association. Diagnostic and statistical manual of mental disorders: DSM-IV-TR. Washington, DC: American Psychiatric Association; 2000

42. Albert MS, DeKosky ST, Dickson D, Dubois B, Feldman HH, Fox NC, Gamst A, Holtzman DM, Jagust WJ, Petersen RC, et al. The diagnosis of mild cognitive impairment due to Alzheimer's disease: recommendations from the National Institute on Aging-Alzheimer's Association workgroups on diagnostic guidelines for Alzheimer's disease. Alzheimers Dement. 2011;7: 270-9.

43. Hunter DC, Burritt D. Polyamines of plant origin - an important dietary consideration for human health; 2011.

44. Til HP, Falke HE, Prinsen MK, Willems MI. Acute and subacute toxicity of tyramine, spermidine, spermine, putrescine and cadaverine in rats. Food Chem Toxicol. 1997;35:337-48.

45. Ishida S, Sarada M, Seki H, McGirr L, Lau A, Morishita K. Genotoxicity and subchronic oral toxicity of L-ornithine monohydrochloride. Regul Toxicol Pharmacol. 2013;67:360-71.

46. Buyukuslu N, Hizli H, Esin K, Garipagaoglu M. A cross-sectional study: nutritional polyamines in frequently consumed foods of the Turkish population. Foods. 2014;3:541-57.

47. Ali MA, Poortvliet E, Strömberg R, Yngve A: Polyamines: total daily intake in adolescents compared to the intake estimated from the Swedish Nutrition Recommendations Objectified (SNO). Food Nutrition Research 2011, 55: https://doi.org/10.3402/fnr.v3455i3400.5455.

48. Marks SM, Lockhart SN, Baker SL, Jagust WJ. Tau and beta-amyloid are associated with medial temporal lobe structure, function, and memory encoding in normal aging. J Neurosci. 2017;37:3192-201.

49. Yassa MA, Lacy JW, Stark SM, Albert MS, Gallagher M, Stark CE. Pattern separation deficits associated with increased hippocampal CA3 and dentate gyrus activity in nondemented older adults. Hippocampus. 2011;21:968-79.

50. Stark SM, Stevenson R, Wu C, Rutledge S, Stark CE. Stability of age-related deficits in the mnemonic similarity task across task variations. Behav Neurosci. 2015;129:257-68.

51. Polcher A, Frommann I, Koppara A, Wolfsgruber S, Jessen F, Wagner M. Face-name associative recognition deficits in subjective cognitive decline and mild cognitive impairment. J Alzheimers Dis. 2017;56: 1185-96.

52. Folstein M, Folstein S, McHugh P. "Mini-mental state": a practical method for grading the cognitive state of patients for the clinicians. J Psychiatr Res. 1975:12:189-98

53. Wechsler D. WMS-R manual: Wechsler memory scale - revised. San Antonio: Psychological Corporation/Harcourt Brace Jovanovich; 1987.

54. Reitan RM. Validity of the trailmaking test as an indication of organic brain damage. Percept Mot Skills. 1955:8:271-6.

55. Lawton MP, Brody EM. Assessment of older people: self-maintaining and instrumental activities of daily living. Gerontologist. 1969;9:179-86.

56. Yesavage JA, Brink TL, Rose TL, Lum O, Huang V, Adey M, Leirer VO. Development and validation of a geriatric depression screening scale: a preliminary report. J Psychiatr Res. 1982;17:37-49. 
57. Borm GF, Fransen J, Lemmens WA. A simple sample size formula for analysis of covariance in randomized clinical trials. J Clin Epidemiol. 2007;60: 1234-8.

58. Champely S, Ekstrom C, Dalgaard P, Gill J, Wunder, J., De Rosario H: pwr: basic functions for power analysis. R package. CRAN 2015.

59. Jessen F, Spottke A, Boecker H, Brosseron F, Buerger K, Catak C, Fliessbach K, Franke C, Fuentes M, Heneka MT, et al. Design and first baseline data of the DZNE multicenter observational study on predementia Alzheimer's disease (DELCODE). Alzheimers Res Ther. 2018;10:15.

60. Marchant NL, Barnhofer T, Klimecki OM, Poisnel G, Lutz A, Arenaza-Urquijo E, Collette F, Wirth M, Schild AK, Coll-Padros N, et al. The SCD-Well randomized controlled trial: Effects of a mindfulness-based intervention versus health education on mental health in patients with subjective cognitive decline (SCD). Alzheimers Dement (N Y). 2018;4:737-45.

61. Poisnel G, Arenaza-Urquijo E, Collette F, Klimecki OM, Marchant NL, Wirth M, de La Sayette V, Rauchs G, Salmon E, Vuilleumier P, et al. The Age-Well randomized controlled trial of the Medit-Ageing European project: Effect of meditation or foreign language training on brain and mental health in older adults. Alzheimers Dement (N Y). 2018:4:714-23.

62. Winkler G, Doring A. Validation of a short qualitative food frequency list used in several German large scale surveys. Z Ernahrungswiss. 1998;37:234-41.

63. Willett WC, Sampson L, Stampfer MJ, Rosner B, Bain C, Witschi J, Hennekens $\mathrm{CH}$, Speizer FE. Reproducibility and validity of a semiquantitative food frequency questionnaire. Am J Epidemiol. 1985;122:51-65.

64. Tripolt NJ, Stekovic S, Aberer F, Url J, Pferschy PN, Schroder S, Verheyen N, Schmidt A, Kolesnik E, Narath SH, et al. Intermittent fasting (alternate day fasting) in healthy, non-obese adults: protocol for a cohort trial with an embedded randomized controlled pilot trial. Adv Ther. 2018;35:1265-83.

65. Märschenz S. Implementation of "NeuroHub" pre-analytics and biomarker management platform for clinical studies allows efficient monitoring of preanalytical sample quality. In: Poster presented at: Global Biobank Week Towards Harmony in Biobanking. Stockholm: BBMRI-ERIC, ESBB, ISBER; 2017.

66. Weygandt M, Meyer-Arndt L, Behrens JR, Wakonig K, Bellmann-Strobl J, Ritter K, Scheel M, Brandt AU, Labadie C, Hetzer S, et al. Stress-induced brain activity, brain atrophy, and clinical disability in multiple sclerosis. Proc Natl Acad Sci U S A. 2016:113:13444-9.

67. Wu WC, Fernandez-Seara M, Detre JA, Wehrli FW, Wang J. A theoretical and experimental investigation of the tagging efficiency of pseudocontinuous arterial spin labeling. Magn Reson Med. 2007;58:1020-7.

68. Chechko N, Drexler El, Voss B, Kellermann T, Finkelmeyer A, Schneider F, Habel U. Neural correlates of unsuccessful memory performance in $\mathrm{MCl}$. Front Aging Neurosci. 2014;6:201.

69. Sperling RA, Bates JF, Chua EF, Cocchiarella AJ, Rentz DM, Rosen BR, Schacter DL, Albert MS. fMRI studies of associative encoding in young and elderly controls and mild Alzheimer's disease. J Neurol Neurosurg Psychiatry. 2003;74:44-50.

70. Sperling R. Functional MRI studies of associative encoding in normal aging, mild cognitive impairment, and Alzheimer's disease. Ann N Y Acad Sci. 2007:1097:146-55.

71. Yushkevich PA, Pluta JB, Wang H, Xie L, Ding SL, Gertje EC, Mancuso L, Kliot D, Das SR, Wolk DA. Automated volumetry and regional thickness analysis of hippocampal subfields and medial temporal cortical structures in mild cognitive impairment. Hum Brain Mapp. 2015;36:258-87.

72. Pietrocola F, Malik SA, Marino G, Vacchelli E, Senovilla L, Chaba K, NisoSantano M, Maiuri MC, Madeo F, Kroemer G. Coffee induces autophagy in vivo. Cell Cycle. 2014;13:1987-94

73. Marino G, Pietrocola F, Eisenberg T, Kong Y, Malik SA, Andryushkova A, Schroeder S, Pendl T, Harger A, Niso-Santano M, et al. Regulation of autophagy by cytosolic acetyl-coenzyme a. Mol Cell. 2014;53:710-25.

74. Guralnik JM, Ferrucci L, Pieper CF, Leveille SG, Markides KS, Ostir GV Studenski S, Berkman LF, Wallace RB. Lower extremity function and subsequent disability: consistency across studies, predictive models, and value of gait speed alone compared with the short physical performance battery. J Gerontol A Biol Sci Med Sci. 2000;55:M221-31.

75. Beaudart C, Reginster JY, Slomian J, Buckinx F, Dardenne N, Quabron A, Slangen C, Gillain S, Petermans J, Bruyere O. Estimation of sarcopenia prevalence using various assessment tools. Exp Gerontol. 2015;61:31-7.

76. Barthel H, Meyer PT, Drzezga A, Bartenstein P, Boecker $H$, Brust $P$, Buchert $R$, Coenen HH, la Fougere C, Grunder G, et al. German Society of Nuclear Medicine procedure guideline on beta-amyloid brain PET imaging. Nuklearmedizin. 2016;55:129-37.
77. Muller-Gartner HW, Links JM, Prince JL, Bryan RN, McVeigh E, Leal JP, Davatzikos C, Frost JJ. Measurement of radiotracer concentration in brain gray matter using positron emission tomography: MRI-based correction for partial volume effects. J Cereb Blood Flow Metab. 1992;12:571-83.

78. Gonzalez-Escamilla G, Lange C, Teipel S, Buchert R, Grothe MJ. Alzheimer's disease neuroimaging I: PETPVE12: an SPM toolbox for partial volume effects correction in brain PET - application to amyloid imaging with AV45PET. Neuroimage. 2017;147:669-77.

79. Villemagne VL, Ong K, Mulligan RS, Holl G, Pejoska S, Jones G, O'Keefe G, Ackerman U, Tochon-Danguy H, Chan JG, et al. Amyloid imaging with (18) F-florbetaben in Alzheimer disease and other dementias. J Nucl Med. 2011; 52:1210-7.

80. Molinuevo JL, Rabin LA, Amariglio R, Buckley R, Dubois B, Ellis KA, Ewers M, Hampel H, Klöppel S, Rami L, et al. Implementation of subjective cognitive decline criteria in research studies. Alzheimer's Dementia. 2017;13:296-311.

81. Rabin LA, Smart CM, Crane PK, Amariglio RE, Berman LM, Boada M, Buckley RF, Chetelat G, Dubois B, Ellis KA, et al. Subjective cognitive decline in older adults: an overview of self-report measures used across 19 international research studies. J Alzheimers Dis. 2015;48(Suppl 1):S63-86.

82. Sachs-Ericsson N, Blazer DG. The new DSM-5 diagnosis of mild neurocognitive disorder and its relation to research in mild cognitive impairment. Aging Ment Health. 2015;19:2-12.

83. Sojkova J, Zhou Y, An Y, Kraut MA, Ferrucci L, Wong DF, Resnick SM. Longitudinal patterns of beta-amyloid deposition in nondemented older adults. Arch Neurol. 2011;68:644-9.

84. Posner H, Curiel R, Edgar C, Hendrix S, Liu E, Loewenstein DA, Morrison G, Shinobu L, Wesnes K, Harvey PD. Outcomes assessment in clinical trials of Alzheimer's disease and its precursors: readying for short-term and longterm clinical trial needs. Innovations Clin Neurosci. 2017;14:22-9.

85. Folstein MF, Folstein SE, McHugh PR. "Mini-mental state": a practical method for grading the cognitive state of patients for the clinician. J Psychiatr Res. 1975;12:189-98.

86. Gauggel S, Birkner B. Validität und Reliabilität einer deutschenVersion der Geriatrischen Depressionsskala (GDS). Z Klin Psychol. 1999;28:18-27.

87. Farias Tomaszewski S, Mungas D, Reed BR, Cahn-Weiner D, Jagust W, Baynes K, DeCarli C. The measurement of everyday cognition (ECog): scale development and psychometric properties. Neuropsychology. 2008;22:53144.

88. Valenzuela MJ, Sachdev P. Assessment of complex mental activity across the lifespan: development of the Lifetime of Experiences Questionnaire (LEQ). Psychol Med. 2007;37:1015-25.

89. Wilson R, Barnes L, Bennett D. Assessment of lifetime participation in cognitively stimulating activities. J Clin Exp Neuropsychol. 2003;25:634-42.

90. Rammstedt B, Kemper CJ, Klein MC, Beierlein C, Kovaleva A. Eine kurze Skala zur Messung der fünf Dimensionen der Persönlichkeit: Big-Five-Inventory-10 (BFI-10). GESIS Working Papers 2012|23. Köln: GESIS; 2012.

91. Janke W, Erdmann G. SVF 78: eine Kurzform des Stressverarbeitungsfragebogens SVF 120; Kurzbeschreibung und grundlegende Kennwerte; Manual. Göttingen; Bern; Toronto; Seattle: Hogrefe, Verlag für Psychologie; 2002

92. Oldfield RC. The assessment and analysis of handedness: the Edinburgh inventory. Neuropsychologia. 1971;9:97-113.

93. Hessler J, Jahn T, Kurz A, Bickel H. The MWT-B as an Estimator of Premorbid Intelligence in $\mathrm{MCl}$ and Dementia. Zeitschrift für Neuropsychologie. 2013;24: 129-37.

94. Helmstaedter C, Lendt M, Lux S. Verbaler Lern-und Merkfähigkeitstest (VLMT). Göttingen: Beltz; 2001.

95. Baddeley AD, Emslie H, Nimmo-Smith I, Thames Valley Test C. Doors and people: a test of visual and verbal recall and recognition. Bury St Edmunds: Thames Valley Test Company; 1994.

96. Wechsler D. Manual for the Wechsler adult intelligence scale-revised (WAISR). San Antonio: The Psychological Corporation; 1981.

97. Schelling D. Block-Tapping-Test. Frankfurt: Swets Test Service GmbH; 1997

98. Bäumler G. Farb-Wort-Interferenztest (FWIT) nach J. R. Stroop. Göttingen: Hogrefe; 1985.

99. Zimmermann P, Fimm B. Testbatterie zur Aufmerksamkeitsprüfung (TAP). Würselen: Psytest; 2012.

100. Morris JC, Heyman A, Mohs RC, Hughes JP, van Belle G, Fillenbaum G, Mellits ED, Clark C. The Consortium to Establish a Registry for Alzheimer's Disease (CERAD). Part I. Clinical and neuropsychological assessment of Alzheimer's disease. Neurology. 1989;39:1159-65. 
101. Frey I, Berg A, Grathwohl D, Keul J. Freiburg questionnaire of physical activity--development, evaluation and application. Soz Praventivmed. 1999; 44:55-64.

102. Buysse DJ, Reynolds CF 3rd, Monk TH, Berman SR, Kupfer DJ. The Pittsburgh Sleep Quality Index: a new instrument for psychiatric practice and research. Psychiatry Res. 1989;28:193-213.

103. Schröder H, Fitó M, Estruch R, Martínez-González MA, Corella D, SalasSalvadó J, Lamuela-Raventós R, Ros E, Salaverría I, Fiol M. A short screener is valid for assessing Mediterranean diet adherence among older Spanish men and women. J Nutr. 2011;141:1140-5.

104. Hebestreit K, Yahiaoui-Doktor M, Engel C, Vetter W, Siniatchkin M, Erickson N, Halle M, Kiechle M, Bischoff SC. Validation of the German version of the Mediterranean Diet Adherence Screener (MEDAS) questionnaire. BMC Cancer. 2017;17:341.

105. Stöber J. Besorgnis: Ein Vergleich dreier Inventare zur Erfassung allgemeiner Sorgen. Zeitschrift für differentielle und diagnostische Psychologie. 1995;16: $50-63$.

106. Glöckner-Rist A, Rist F. Deutsche Version des Penn State Worry Questionnaire (PSWQ-d). In: Danner D, Glöckner-Rist A, editors. Zusammenstellung sozialwissenschaftlicher Items und Skalen; 2014.

107. Kühner C, Huffziger S, Nolen-Hoeksema S. RSQ-D: Response styles questionnaire - deutsche Version. Manual: Hogrefe; 2007.

108. Spielberger CD, Gorsuch RL, Lushene RE. Manual for the state-trait anxiety inventory; 1970

109. Bullinger M, Kirchberger I: Fragebogen zum Gesundheitszustand: SF-36. Hogrefe, Verlag für Psychologie; 1998

110. Angermeyer MC, Kilian R, Matschinger H. WHOQOL-100 und QHOQOL-BREF: Handbuch für die deutschsprachige Version der WHO Instrumente zur Erfassung von Lebensqualität. Göttingen: Hogrefe; 2000.

111. Pietrocola F, Castoldi F, Maiuri MC, Kroemer G. Aspirin-another caloricrestriction mimetic. Autophagy. 2018;14(7):1162-63.

112. Troyer AK, Rich JB. Psychometric properties of a new metamemory questionnaire for older adults. J Gerontol B Psychol Sci Soc Sci. 2002;57: P19-27.

113. Guralnik JM, Simonsick EM, Ferrucci L, Glynn RJ, Berkman LF, Blazer DG, Scherr PA, Wallace RB. A short physical performance battery assessing lower extremity function: association with self-reported disability and prediction of mortality and nursing home admission. J Gerontol. 1994;49:M85-94.

Ready to submit your research? Choose BMC and benefit from:

- fast, convenient online submission

- thorough peer review by experienced researchers in your field

- rapid publication on acceptance

- support for research data, including large and complex data types

- gold Open Access which fosters wider collaboration and increased citations

- maximum visibility for your research: over $100 \mathrm{M}$ website views per year

At BMC, research is always in progress.

Learn more biomedcentral.com/submissions 